\title{
Supplemental Work at Home among Finnish Wage Earners: Involuntary Overtime or Taking the Advantage of Flexibility?
}

\section{Satu Ojala}

Researcher, School of Social Sciences and Humanities, University of Tampere, Finland

\begin{abstract}
It is suggested, that the new flexible work practices are enhanced to meet the work-family demands and therefore benefit especially women. In the article the focus is on informal flexibility taking place at home, for which field studies of the role of gender are rare. Against the assumptions, paid work at home is mostly informal, supplementary overtime by nature. In this article, I explore why employees undertake work in their private sphere during their free time and whether gender makes a difference there. I carry out both qualitative and quantitative analyses. The qualitative data consists of 21 interviews with white-collar employees and the quantitative data from the Finnish Quality of Work Life survey 2008 for which there are almost 4400 respondents. The methods include content analysis, descriptive statistics and logistic regression analysis.

According to both the qualitative and quantitative data, job characteristics play the most important role for all who work at home; employees with higher education, or supervisory tasks, in parallel with having an autonomous and inspiring job predict both tele- and supplemental work. Importantly, gender plays only a minor role in the puzzles of choosing when and where to work. The social relations at the workplace, including the atmosphere and the support of superiors and the work community, are only weakly related to work at home. At the same time, supplemental work is associated with great time pressure and involuntary overtime.
\end{abstract}

\section{KEY WORDS}

Formal and informal flexibility / gender / supplemental work at home / telework / working time / content analysis / logistic regression analysis / Finland.

\section{Introduction}

ork is increasingly becoming disconnected from a particular time and place. While work used to be carried out mainly at the employer's premises, it is now carried out in other locations for example at home, while travelling or at a customer's place. Over half of all European workers spend at least some of their working time outside employer's premises (Parent-Thirion et al. 2007; Hislop and Axtell 2007). One of the most common spheres for work is home.

Many of the previous studies concerning home-based work have focused on telework. Since the 1970s, telework at home or, for example, at satellite offices has been

Satu Ojala, School of Social Sciences and Humanities, FIN-33014, University of Tampere, Finland. E-mail: satu.ojala@uta.fi 
seen as a solution to many work-related problems from congestion to reconciling work and family (Pyöriä 2006). After an era of clear division between domestic spheres and factory-located work, work certainly has taken a leap back to home (Felstead et al. 2005, p. 41-44). However, as Nätti et al. (2011) found out, the nature of this return to working at home has not only been telework, but also more informal overtime.

In this article I explore why employees undertake informal supplemental work practices at home beyond their formal working time and place. The Finnish quality of work life survey with almost 4400 respondents presents an opportunity to study informal overtime carried out at home. To answer the question as to why employees engage in supplemental work, I also analyze data from qualitative interviews carried out with 21 white-collar workers.

This article is organised as follows: First, I discuss the features of much work today that enable and increase work at multiple spaces. I also specify the conceptualisation and illustrate the extent of supplemental work. Second, the research design of this study is described. Third, I present the results of both qualitative and quantitative analysis. In the fourth discussion part, I draw together the results and discuss the implications.

\section{Fragmenting time - dispersing work}

The rise in the educational levels and availability of IT in all prosperous countries is connected with the change of much work towards knowledge-based organizing. Knowledge-based work, for one's part, escalates the accustomed borders of working time and place. Knowledge-intensive work tasks encompass a need for high-level creativity, as well as for handling and creating multi-level knowledge and sharing it with team members and customer networks (Hislop 2008; Pyöriä 2006; Alvesson 2004).

The foundation of this article is closely tied to the intangible nature of knowledge work. All work today covers a wide range of informal and even uncontrollable practices, starting with work-related thinking and planning during one's free time. The nature of work including the use of tacit contextual knowledge and multi-level skills does not alleviate attempts to measure and plan work strictly. Time is split into pieces, which lead to the continuation of work-related tasks in the private sphere and vice versa. As O'Carroll (2008) remarks, there is a mismatch between the need to quantify the work processes and the qualitative nature of time associated with knowledge-intensive work.

The confusion with the nature of much work also pertains to the flexibility enhanced by international actors like the European Union and working organizations in practice. The EU has launched new programs and strategies for working lives, with one central outcome being the flexicurity policies. Flexibility and security are provided as a strategic mixture aiming at more flexible labour markets without weakening employees' rights and status. In accordance, some changes have taken place at the organizational level. Flexibilisation interconnects with the change in new forms of managing labour (e.g. van Echtelt et al. 2006). According to Thompson (2003), the most essential changes in organizations are, firstly, the shift to flexible knowledge-based production, networking and decentralisation of units; and secondly, at the employee level, the distribution of responsibility to employees to make them more committed and self-disciplined.

Increased responsibility and autonomy though leads to contradictory outcomes and may create 'autonomy paradoxes': the more responsibility the employees get, the more they enjoy their work and the longer their working hours get (van Echtelt et al. 2006). 
The more pessimistic view related, expressed by Sennett (1998), stresses that this type of flexibilisation is generated at the expense of employees who give their devotion without reciprocal rewards from their employers. However any empirical evidence does not show systematical misuse of employees but rather rise in both employee autonomy and related well-being levels, albeit alongside higher levels of time pressure (e.g. Green 2006; Lehto and Sutela 2008).

\section{Informal overtime at home}

To get a closer look at one specified, flexibility-enhanced work practice, I now focus on work at home. It is noted (Nätti et al. 2011; 2009), that by nature, home-based work is more often informal overtime-related supplemental work than formal telework. Thereby work at home constitutes an important view in the study of the contradictory nature and outcomes of flexible organization of work.

Supplemental work at home, conceptualized by Sullivan (2003) and Fenner and Renn (2010), refers to unsigned and thus informal work beyond contracted hours in an employees' own time and space. This means working outside of the workplace, early mornings, evenings, nights, weekends or on vacation. The concept differs from pure overtime, which more often may get carried out at a workplace as an agreed practice. The informality of supplemental work consists of its non-agreed and thereby partly hidden nature. Employees may carry out work without necessarily asking for any compensation. Practically, the Finnish confederation for professional trade unions have calculated that all uncompensated overtime working may be worth 7800 euros per professional employee a year and thus reduce tax revenues as much (Akava 2008).

However, it is unclear whether supplementary work can be directly regarded as unpaid or uncompensated. The present-day employment contracts may be based on the performing of certain tasks rather than on the specified use of time at a workplace. Pertaining to all unpaid overtime, some rewards such as higher salaries or promotions may take place afterwards (Campbell and van Wanrooy 2010). In a study focusing on overtime work at home it was also shown that employees undertaking unpaid overtime expected to end up with better positions and wages (Song 2009).

Conceptually supplemental work is close to telework, which after four decades of studies now often gets conceptualized as working from a distance at an employee's own premises and under an oral or written contract (e.g. Sullivan 2003; Sullivan and Smithson 2007). Formal flexible practices such as telework are largely seen to be to the advantage both employers and employees (Pyöriä 2006), even though, the feasibility of flexible practices varies largely by status and work tasks. Telework in general is studied extensively, however the difference between formal telework and informal work at home has not been widely recognized. In particular, quantitative studies concerning supplemental work, as well as other informal practices, have been infrequent due to the lack of data that separates tele- and supplemental work, however some important findings have come about (Song 2009; Fenner and Renn 2010; Boswell and Olson-Buchanan 2007). In many national and international surveys, there is a lack of appropriate questions targeting informal forms of paid work, which may reflect difficulties in keeping on top of the unforeseeable puzzles that evolve with the larger availability of technology-enhanced knowledge work.

Based on the European working conditions survey, full time telework stands at a very low level of one to two percent on average in 31 European countries and at about 
two to three percent in Finland; part-time telework averages $15 \%$ in the EU25, all Nordic countries showing somewhat higher levels (Parent-Thirion et al. 2007). Comparative results on the diversification of work at home between formal and informal parts do not exist. Yet, according to the Finnish quality of work life survey from 2008, reported on by Nätti et al. (2009), over a half of all homeworkers $(54 \%)$ reported that the nature of their work at home was usually overtime without compensation. A third of homeworkers were teleworkers and a tenth of these employees engaged in both tele- and supplemental work. No remarkable temporal changes in either tele- or supplemental work have taken place since 1990, although the share of employees working at home has increased somewhat. (Nätti et al. 2009.)

To further characterize home-based work, the aforementioned Finnish study (Nätti et al.2009) shows that supplemental work mostly pertains to high level white-collar workers: in 2008 more than two thirds (70\%) of high-level white-collar employees did supplemental work occasionally. Parallel findings from the United States, by Song (2009), show that having a high education, the lack of overtime rates, being a team leader, efficiency wages, and earnings inequality in an occupation define the character of unpaid work at home. Therefore, supplemental work is part of the autonomic nature of work and tasks that are detachable from a certain time and place. Another possible association relates to the role of organizational 'time cultures' in which, case-specifically, overtime may shape everyday work as an established practice (e.g. Alvesson 2004; Julkunen et al. 2004).

Definite reasons for unpaid overtime have been looked at in a few studies. According to Song (2009), the main reason for unpaid work at home was the need to finish or catch up on work. In relation to this, Campbell and van Wanrooy (2010) found that extra unpaid hours coexist with the combination of workload, autonomous time use and possibly some new indirect forms of organizational control. In addition, Boswell and Olson-Buchanan (2007) found, that ambition and job involvement significantly gave motivation for IT-assisted after-hours working. Among the American homeworking mothers, one fifth also mentioned 'coordinating work with personal/family needs' (Wight and Raley 2009).

\section{Gender and work at home}

The role of gender in the formation of everyday flexibility is discussed extensively. The key conflict, when focusing on work at home, is whether this work takes place to enhance a better work-life balance and thereby enable women to access labour markets, when they would be otherwise restricted due to child-care responsibilities; or whether it is practiced only to meet the requirements of work, resulting in the reinforcement of gendered work and family roles. (E.g. Morganson et al. 2010; Sullivan and Smithson 2007; Vittersø et al. 2003; Mirchandani 2000.) The divergence in findings may result from varying organizational working conditions as well as different national labour market and cultural structures, or from individual ways to react to employee-friendly flexibility once offered.

The lifestyle preferences of both women and men, conceptualized by Hakim (2002) as being home-centered, work-centered, or adaptive, may shape flexible working choices in particular. For professional women with children, work at home may form a pathway to dual-centricism involving both parents' careers and children's lives (Kossek et al. 2006). Similar results were found for high-status men with children who work 
from home (Halford 2005): the intertwining of work and home was positively regarded among them as well as among their managers', implying a renegotiation of work-home boundaries rather than a collapse of them. The finding by Halford also indicatively reflects a change in fatherhood in favour of children.

However, it was noted by Atkinson and Hall (2009) that the forms of flexibilities available differ by gender: breadwinner male employees in high positions took advantage of informal work outside the customary working environments beyond their tightly scheduled workdays. Meanwhile, formal flexibility was more frequently provided for women as it was intuitively considered to be a womens' issue. At the same time, Wight and Raley (2009) found out that when choosing where to work, work requirements came before parenthood among both men and women.

A few indications on the role of gender in respect to working informally at home have come about. Song (2009) found out that women did not undertake any more unpaid work at home than men. Furthermore, Atkinson and Hall (2009) address the fact that informal flexibility arises as a result of certain status and tasks rather than of gender, however men's status both in work and in the family more often leads to informal work. This finding suggests that patterns of informal actions may formulate differently than in a case of formal flexibility. In the next sections, I examine both qualitative and quantitative interview data to characterize work at home in more detail and in general.

\section{Research design}

I ask, firstly, why employees undertake supplemental actions at home after or before the actual work time, and secondly, which factors and characteristics of both the work itself and the employee are associated with supplemental work in general. The main tension to be examined is whether supplemental work is more a question of enthusiastic working or whether the requirements of work, for example time pressure, end up in informal overtime at home. In addition, due to the small amount of studies that differentiate between more formal telework and supplemental overtime, I study the relations between these two forms of home-based work using a combination of different data.

The data consists of both qualitative and quantitative interview data. The qualitative data consists of interviews with 21 highly skilled white collars. The data was gathered in 2005. The thematic interviews handled questions of time squeeze from different perspectives. The experiences of busyness, breaking away from work for leisure, work at home and reconciling work and other life spheres were discussed. The group of employees was chosen according to the potentially mobile nature of their work. The interviewees worked mostly within the large Finnish public sector in the fields of research, education, in libraries and state and local administration, one quarter of them in supervisory positions; a few private sector employees, two journalists, a project designer, two engineers and one manager, were involved. The employees come from various backgrounds with differing work experiences and family situations. There were five men aged 32 to 54 years and 16 women aged between 26 and 55 years. Single, married and cohabiting couples, families with children and lone mothers and fathers are included.

The qualitative analysis focuses on supplemental work. Data was firstly coded with Atlas.ti software to gather all data concerning work at home. These sections and their contexts where then analyzed with data-driven content analysis tools to generate larger 
categories and to name the diverging dimensions for overtime work at home space. Three major categories were found. Within these categories, nuances were further analyzed in more detail. The major categories serve as the basis for the quantitative analysis.

The Finnish Quality of Work Life quantitative survey data (FQWLS, N=4392) from 2008 is representative of all Finnish employees aged between 16 and 64 years (Lehto and Sutela 2008). This high quality data has been collected every four or five years since 1977. The data provides internationally exceptional questions about the nature of informal overtime work at home.

The quantitative methods include descriptive and logistic regression analysis. To find out whether the nature of work plays a role in home-based work practices, I study supplemental and telework in separate logistic models. To further investigate the role of gender, the models are run separately for men and women. Logistic regression enables the estimation of probable differences between groups with a dichotomised dependent variable. For the categorised independent variables a reference group is chosen. The reference group gets the odds ratio value of 1.0 and other groups are compared to this. The odds ratio value $(\operatorname{Exp} B)$ indicates an increase $(>1.0)$ or decrease $(<1.0)$ in the odds of the phenomenon occurring compared to the reference group (1.0). The odds ratio is often mistakenly referred to as probability (Rita and Komonen 2008); the odds ratios may theoretically rise up to about 380 units in the case that, for example, all women and no men worked at home. Thereby the probability should be separately counted from the odds ratio values.

The original variable asks whether the nature of work carried out at home is mainly overtime work without compensation, or whether it has been agreed that some of the working hours are worked at home, or whether both options are encompassed. The question is directed only at employees who work occasionally or partially at home. Full-time homeworkers ( $\mathrm{n}=72,1.6 \%$ of all employees in the data) are thus, due to this limitation of the data, included in the reference group of the dependent variable.

The controlled variables consist of themes based on previous research and on the qualitative results in the first part of the analysis. The controlled themes gather around personal, job and work community characteristics. Besides including these measures, the model is also built exploratively step-by-step with the aim of looking for possible unforeseen relations. The utilized variables are described in accordance with the presentation of the results. For the creation of the sum variables, principal components analysis was also applied, yet not presented here, and reliability tests were carried out. Sum variables are presented as ascending scale variables. The small amount of missing values in the dependent variable $(n=4)$ and in the controlled categorized variables are excluded. The missing values in the sum variables are coded into the average. The correlation matrix for the controlled variables included is presented in Appendix 1. The list of controlled but non-significant variables is presented in Appendix 2.

\section{Results}

\section{Part I, Qualitative results}

According to the qualitative analysis, three main accumulating categories of motivations for supplemental work are found. The most positively described supplemental 
work is enthusiasm-based and can be described as a voluntary practice. The second group of reasons gathers around indefinite nature of much knowledge-based work, in association with the inestimable time it takes to finish immaterial tasks. Thirdly, the time culture at the work organization plays a role in formulating the choices of timing and location of work.

\section{Highly motivated: "I don't count the hours'}

Many of the interviewed highly skilled employees enjoy their work as much as if it were their hobby. The accustomed boundaries of work and non-work are stretched in many ways. Apart from the paid work -related tasks the employees carry out regardless of time and place such as reading email, they also participate in professional activities outside work and do work-like tasks, for example translations or write public journal articles, for some extra income. Also the need to keep up with the latest developments, that is reading newspapers, new research or occupational magazines, is positively charged and usual practice carried out during their own time. Yet there is a kind of precondition in many knowledge-intensive occupations that employees must know the current public debate related to work, whereas formal working time is prioritized for more visible and measurable tasks. These practices indicate that professional skills are voluntarily utilized and developed outside paid work, during one's free time. 'Well, at work or at my leisure, it's my hobby', explains a 55-year-old manager.

Referring to paid work itself, almost all of the interviewed employees describe systematic planning of work during their free time.

You do brainwork also in the evenings. You plan, you think, look for solutions, something that came out during the day, you work it out, sometimes even take a pencil and a paper, to remember, you got a good idea [...] I don't think of it as work, I don't count. (Senior researcher, $48 \mathrm{M}$ ) [48 refers to age, $\mathrm{M}$ to male, $\mathrm{F}$ to female]

Voluntary supplemental work is clearly connected to autonomous tasks and occupations. The employees voicing no need to separate work and leisure are mostly either in managerial or in highly specialised positions. Employees enjoy their work with no need for clear - if any - boundaries. One manager even describes her frustrations with working-time related restrictions:

We got this flexible working time and I've got that 80 hours limit filled, and now I shouldn't come to work too early. This is ridiculous! I have to come by ten. I don't know what to do at home. [...] It feels crazy working at home waiting to be allowed to come to the work place. Am I allowed to knit? (Manager, 55F)

This extreme expression can be seen in association with the large amount of tasks the manager has got or has voluntarily taken. Thus, large numbers of tasks attached to the work increase the pressure to work during one's own time: there is a responsibility to meet the needs of customers, employees or students in time. Based on a few expressions, however, it is not clear what the choice concerning informal working would be if there were an option to choose. 
However, there are also employees doing voluntary supplementary work, four of them researchers and one IT professional, all female, who are not burdened with greater responsibility. The IT professional $(44 \mathrm{~F})$, whose tasks are more formally tied to working time and place with no work overload, positively describes working sometimes from home after work, and even going to the intranet of her work place and actually working there. The IT professional's life phase, being single, may play a role. Voluntary supplemental work is less conveyed by employees with families in this data. Both children and spouses, especially in cases of younger employees, seem to preclude voluntary work outside contracted hours. However no clear gender differences can be found: there are both male and female voluntary supplemental workers, even though, as an indicative finding, no one of the younger men included supplemental actions in their days except for reading email every now and then.

\section{Grey areas: 'Getting stressed from my ineffectiveness'}

Most of the employees interviewed prefer to work only during formal hours, however, only a few actually follow this preference strictly. Usually supplemental work results from occasional accumulation of deadlines or other tasks that are compulsive by nature. Those carrying out occasional supplemental work do not enjoy working in their own space: 'Sometimes I take it home but I don't feel good doing it' (coordinator in the field of development, 35F). The employees are not familiar with the idea of work entering their private sphere of recovery and their own time. One researcher feared that if she brought one task home it may have a kind of knock on effect and she would end up bringing more and more work home with her.

Except for the purpose of gathering tasks that cannot wait, the phenomenon of supplemental work covers many features of intangible work. As shown by Song (2009), the indefinite categories 'nature of work' as well as a related category of 'finishing or catching up on work' are associated with supplemental work. In this data, these two aspects are entangled with each other. Employees describe working after hours to get rid of work-related thoughts: unfinished tasks need to get done in order to break away from them mentally. This is partly related to the inability to estimate the time needed for a certain working task, as condensed by O'Carroll (2008): the need for quantitatively calculable results does not fit with the immaterial tasks being more qualitative by nature.

Though enthusiastic, the unbound nature of work creates a sense of being under compulsion:

If I'm working on a piece of research, I'm unable to cut off thinking. [...] And when the idea comes, you must get up and write it down, even in the small hours, and then go back to sleep. (Project manager, 52M)

Later on, the project manager describes his frustration towards his work that does not respect any emotional attempts to keep it at work place. Even breaking off work during holidays was disturbed. Years of independent and thus intriguing work have led to senses of giving work too much attention, at the expense of other life spheres. The need for sufficient time for getting rid of and recovering from work is obvious. This narration 
refers to the entanglement which is described positively and negatively at the same time: fascinating work ends up with senses of exhaustion and tiredness.

One of the grey areas of supplemental work relates to the continuing evaluation of one's own work effort:

If I'm in a hurry, I think it's my own fault, I've been bad at organizing. [...] After a moment of recovery, I work for a while at home, but it's time for myself, nobody pays me for that. But I usually do it for compensation too. If I've had lazy day at work, I feel I owe my employer something, somehow. Getting stressed from my ineffectiveness, it helps... (Researcher, 36F)

The researcher suffers from the 'fuzzy holes' described by O'Carroll (2009): tiny moments during the day when nothing measurable takes place. The researcher punishes herself for being ineffective by engaging in supplemental work. She feels that the ineffectiveness she places in herself should somehow be compensated for the employer. But do feelings of guilt bring about effectiveness?

In addition, time taken for just thinking seems unproductive; even employees with tacit and immeasurable tasks long for visible and precise results. Control over one's own work is thus far internalized. In particular, some young female employees among these respondents plague themselves with continuous evaluation.

Furthermore, intangible time related to knowledge-intensive tasks is concurrent with feelings of being rushed and time squeeze. It is unclear whether the sense of being rushed is mostly produced by the employees themselves or whether the organizations also play a role by giving too many tasks. The interest in new tasks may seem irresistible, just as the need to give the impression of being an engaged and thus valued employee may have an impact on overtime.

Often I try to do it all, everything I aim to do. My husband always says that I shouldn't try to do it all, I should drop something [...] no need to do everything that perfectly. But I may slightly have a tendency towards perfectionism... (Researcher, 28F)

Much work embeds a continuous struggle to choose and prioritise between tasks, which may end up being problematic if the employee does not know how or does not have the courage to leave some tasks on the table. Interestingly, here the husband is given the role of preventing the wife from doing supplemental work. The same situation is seen in many interviews: the family helps to set the boundaries between work time and family time, especially if kids are involved. The needs and wishes of the spouses are thus recognised and analysed, however they seem to be easier to bypass in favour of work.

\section{Time culture in the workplace: 'I'm somehow peacocking'}

Organizations play an important role in constituting working time practices. Superiors shape organizational policy with their attitudes and behaviour. The organizations in this data, described through the employees, show a large variation regarding the expectation of or prevention of overtime work. The data provides some evidence of organizational long-hours culture as revealed in previous studies (e.g. Julkunen et al. 2004; Alvesson 2004), yet the opposite is also evident: organizations that actively promote formal working 
time are also described. For example, a 38-year-old project manager tells of the principle which has been promoted by her superior, '... we don't do overtime, therefore the days don't stretch out, even if we have plenty to do'. Principles as clear as this are followed by the employees and when there is a need for occasional overtime, it is negotiated.

A young female journalist describes positively-nuanced conversations with her superior to find ways out of her long working days and involuntary supplemental work both at the workplace and at home. In spite of this, changes in the organization in particular and in the tasks she has to prolong her working days regularly:

We have a kind of a goal that we keep talking about the working conditions with the new administration here, as I don't get any compensation for overtime. I get paid quite a lot but I don't think it's enough to cover my work, all the time. [...] But I strongly believe that things will get better when this system here stabilizes; we had quite a big reform at the beginning of this year and still have plenty to do with it. Nowadays, the way to do things here is much more ambitious and more demanding, and I like it. (Journalist, 26F)

The need for overtime is tolerated temporarily due to big reforms that are in progress as long as the organization engages in sufficient discussion and shows understanding for the employees' position and gives opportunities for self-development. The journalist sees herself as being on top of the situation and finds her supplemental work essential for the success of the reforms. Concurrently she describes her informal practices as the result of both the desires of the organization and of herself. Flexible policies are thus recognized as being advantageous if an understanding over reciprocal flexibility exists (Atkinson and Hall 2009).

However, as in the case of the journalist, in most organizations working times are not actively defined. There are neither exact principles concerning overtime or work at home nor any specific suggestions for engaging in it. Many organizations consequently have no idea of the huge amount their employees are actually doing informally at home. For example, a 48 year-old senior researcher describes vast amounts of work and difficulties with organizing time for example to take his son to the doctor, and then, he reads work papers even while waiting to see the doctor. He engages in supplemental work often after the children have fallen asleep and ends up with problems in switching off from work. However, he does not let the supervisors know the amount of work he ends up doing. Though in Finnish research organizations in general, intolerable amounts of work have become a norm. Supplemental work is thus the most common among education sector employees in Finland (Julkunen et al. 2004).

There are also hints of even more problematic long-hour cultured organizations. A few employees describe regular or occasional pressure set by the employers to work more and longer hours.

I haven't accepted all the tasks they've wanted to give me. I don't want to work overtime, but then it seems that some of the superiors think I'm somehow peacocking and they don't like it. (Lecturer, 32M)

The lecturer also tells of urgent tasks that are delivered to his table at the end of the day with suggestions of having them ready by the next day. There are also unspoken messages and hints encouraging more work. A clear decision made by the employee of 
not to adhere to the hints is even directly challenged and he notices that his place in the hierarchy is questioned. Perhaps exceptionally, the lecturer does not let all of this affect his decision not to follow the informal organizational time culture.

Of course, a long-hour culture in the workplace is somewhat different than the more informal supplemental work at home. As a planning engineer (30M) explains 'it's a kind of firm, you can sit there all day long', there may be different reasons for working longer hours together with other employees. Supplemental work may be more task and deadline-oriented than a result of following organizational time cultures.

All in all, the role of work organizations in shaping the working time and place related practices is ambiguous. Pertaining to knowledge-based tasks, the role of the organization diminishes and employees actively choose between places and the timing of work. However, organizations largely tend to give employees more responsibility and tasks than would fit into limited working hours, which means that it is often followed by supplementary work after hours. Even though tasks are largely shaped by employees themselves, having a time culture with no need for overtime work does not necessarily stop them from engaging in more interesting tasks and from doing supplemental work.

\section{Part II, Quantitative results}

I now examine quantitatively, what kind of features are associated with supplemental work. To understand the special characteristics of supplemental work, the results are presented separately for telework. The three categories resulting from the qualitative analysis are turned into measures in the logistic regression models.

In Table 1, I present the prevalence of the different forms of paid work at home. Altogether one third of all Finnish employees worked at home in 2008 at least partially or occasionally. More than half of this work was overtime work without compensation (supplemental work), one third of the employees working from home had agreed the terms with their employees (telework) and slightly more than $10 \%$ of employees reported doing both (in the ensuing analyses this category is included in supplemental work).

In Table 2, I present the relations of supplemental and telework to working time. Longer than 40 hour working weeks are slightly more common among supplemental workers, especially among men. All homeworkers, excluding teleworking women, have

Table I Prevalence of paid work at home by nature among Finnish employees (FQWLS 2008)

\begin{tabular}{lcccc}
\hline Is the work you carry out at home: & All employess & \multicolumn{3}{c}{ Homeworking } \\
\cline { 2 - 5 } & & women & men & all \\
\hline Overtime work without compensation & $18 \%$ & $54 \%$ & $53 \%$ & $54 \%$ \\
\hline $\begin{array}{l}\text { Or has it been agreed that you work some } \\
\text { of your normal working hours at home }\end{array}$ & $12 \%$ & $33 \%$ & $35 \%$ & $34 \%$ \\
\hline Or both & $4 \%$ & $13 \%$ & $12 \%$ & $12 \%$ \\
\hline Works only at workplace & $66 \%$ & & & $100 \%$ \\
\hline Total & $100 \%$ & $100 \%$ & 704 & 1495 \\
\hline$N$
\end{tabular}


Table 2 Supplemental and telework according to working time descriptives (FQWLS 2008)

\begin{tabular}{|c|c|c|c|c|c|}
\hline & & \multicolumn{2}{|c|}{ Supplemental workers } & \multicolumn{2}{|c|}{ Teleworkers } \\
\hline & & Women & Men & Women & Men \\
\hline \multirow[t]{3}{*}{ Weekly working hours } & 0-40 hours & $88 \%$ & $75 \%$ & $94 \%$ & $81 \%$ \\
\hline & 41 hours or more & $12 \%$ & $25 \%$ & $6 \%$ & $19 \%$ \\
\hline & & $100 \%$ & $100 \%$ & $100 \%$ & $100 \%$ \\
\hline Mean weekly working hours & (all employees 36,8 ) & 37,5 & 40,5 & 35,9 & 38,6 \\
\hline \multirow[t]{6}{*}{ Hours of work at home } & I hour per week & $52 \%$ & $43 \%$ & $27 \%$ & $29 \%$ \\
\hline & 2 hours & $16 \%$ & $23 \%$ & $20 \%$ & $19 \%$ \\
\hline & $3-5$ hours & $21 \%$ & $20 \%$ & $26 \%$ & $28 \%$ \\
\hline & $6-10$ hours & $8 \%$ & $10 \%$ & $18 \%$ & $11 \%$ \\
\hline & more than 10 hours & $4 \%$ & $4 \%$ & $10 \%$ & $13 \%$ \\
\hline & & $101 \%$ & $100 \%$ & $100 \%$ & $101 \%$ \\
\hline \multirow{3}{*}{$\begin{array}{l}\text { I have to do more overtime } \\
\text { work than l'd like to. }\end{array}$} & true & $34 \%$ & $33 \%$ & $17 \%$ & $14 \%$ \\
\hline & untrue & $66 \%$ & $67 \%$ & $83 \%$ & $86 \%$ \\
\hline & & $100 \%$ & $100 \%$ & $100 \%$ & $100 \%$ \\
\hline$N$ & & 529 & 455 & 262 & 249 \\
\hline
\end{tabular}

higher average weekly working hours than the Finnish national average of 36,8 hours, men doing supplementary work do an average of 40,5 hours of work every week. The hours spent working at home are somewhat longer for teleworkers and a quarter of them report working at least 6 hours a week at home. At about half of the supplemental workers report working only one hour per week at home on average, reflecting the occasional nature of supplemental overtime. Men do slightly longer supplemental hours than women, whereas the longer teleworking hours are more common for women. The involuntary nature of overtime work is more related to supplemental than to telework: one third of supplemental workers do more overtime hours than they would have liked to as opposed to $17 \%$ of teleworking women and $14 \%$ of teleworking men.

The logistic regression model in Table 3 is constructed with three categories of controlled variables: personal, job and workplace social relations characteristics. The qualitative results suggested that supplemental work is carried out as the result of high motivation, the need to finish tasks, but also as a result of being busy and having a great amount of tasks. Some implications of the effect of the organization's time culture were addressed. These aspects are operationalized together with the earlier findings by Nätti et al. (2011) and Song (2009) with regard to the labour market position of the employee. The personal features encompass the variables gender, marital status, age and having children under 18 years of age at home. 'Job characteristics' include socioeconomic status and supervisor status. In order to further capture the labour market position of the employee, two subjective measures describing the experienced career advancement opportunities in the current work place and the likelihood of getting a new job are included. To describe the degree of the knowledge-intensive features of the work, a sum variable of being able to apply ones own ideas in work and to take part in the planning of ones own work, is included. After the analysis of many other possibly related features, the aspects 'changes in tasks' and 'time pressure' proved significant. Organization-related variables, such as the sector and the number of personnel were not significantly related to work at home (see Appendix 2). The third group of independent variables centers on the theme 'social relations at work'. A 
large number of supervisory, atmosphere and support-related variables were controlled for, however only a few of them resulted in being significant. The categorization of the variables is presented in Table 3. The variables are presented as the questions that were originally asked. The sum variables are based on principal component analyses.

According to Table 3, the most important factors predicting all work at home are high socio-economic status, supervisor status, and the creative nature of work. The odds ratio that the higher-level white-collar workers do both supplemental and telework at home is 4 to 9 -fold compared to the blue-collar workers. These results are tremendously similar for both women and men.

Personal characteristics show inconsistent associations with work at home. Pertaining to all work at home, men are slightly more likely to work at home. 26 to 35 year-old women, at the age of entering professional labour markets, are a little bit more likely to do supplemental work, a result that is supported by the qualitative analysis. Also older women $(50+)$ show same levels of supplemental work. There is only weak support that men at the age of 36 to 50, during their most intensive career development years, may do supplemental work more often compared to other age groups. The support for the idea that the family characteristics might shape flexibility choices is weak as well. Married or cohabiting women may favour telework more often than others, and children rarely increase the odds ratio for both types of work at home. However it is important to notice that supplemental work is not at all reactive to the family situation.

Besides status and tasks that contain planning and exploring ones own ideas, work at home in general and especially supplemental work is associated with time pressure. In particular, the need to stretch days out of both women and men and an increase in more difficult tasks strongly predict supplemental work, which is stronger among men. Furthermore, telework carried out by men is also associated with higher workplace risks, followed by time pressure pertaining indicatively to male supplemental workers. However, on the whole, telework is not carried out under pressurised circumstances.

Regarding the estimate of informal work being an investment in ones future, based on the studies by Campbell and van Wanrooy (2010) and Song (2009), some interesting evidence arises. The employees who predict that they have good career advancement and employability opportunities were less likely to undertake informal work at home. In contrast, supplemental work is more prevalent among women with fair or poor advancement opportunities at their present workplace. A similar, even stronger connection is found for men who believe their employability opportunities to open labour markets to be only reasonable or poor. These results may signal that the supplemental workers in more unstable positions try to strengthen their position by undertaking more informal work at home. Nevertheless, no emphatic conclusions can be drawn from this result.

Features concerning social relations at work do not show any wide-ranging relationship to home-based work. A competitive spirit in the work community slightly increases the likelihood of doing supplemental work at home in particular. An open atmosphere decreases the likelihood that women will do telework. Interestingly, and as a positive feature, an increase in support from superiors and colleagues decreases supplemental work among women, whereas stronger support for men predicts a slight increase in telework. These results indicatively imply that a confidential atmosphere in the work community may enhance formal telework and constrain the need for informal overtime. However, this evidence is neither systematic nor especially strong. Surprisingly, none of the controlled variables focused on superior work and attitudes are related to any form of home-based work (Appendix 2). 


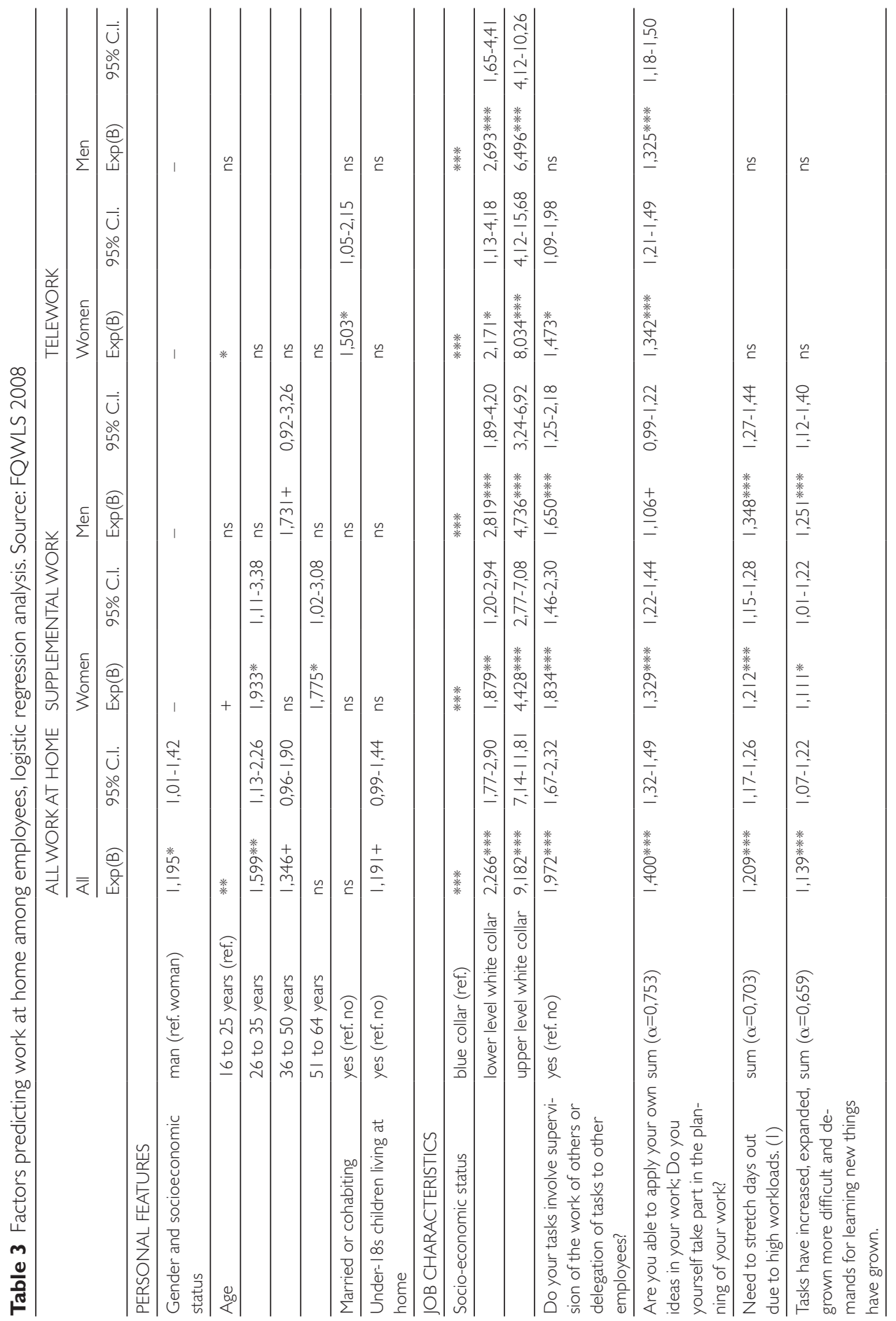




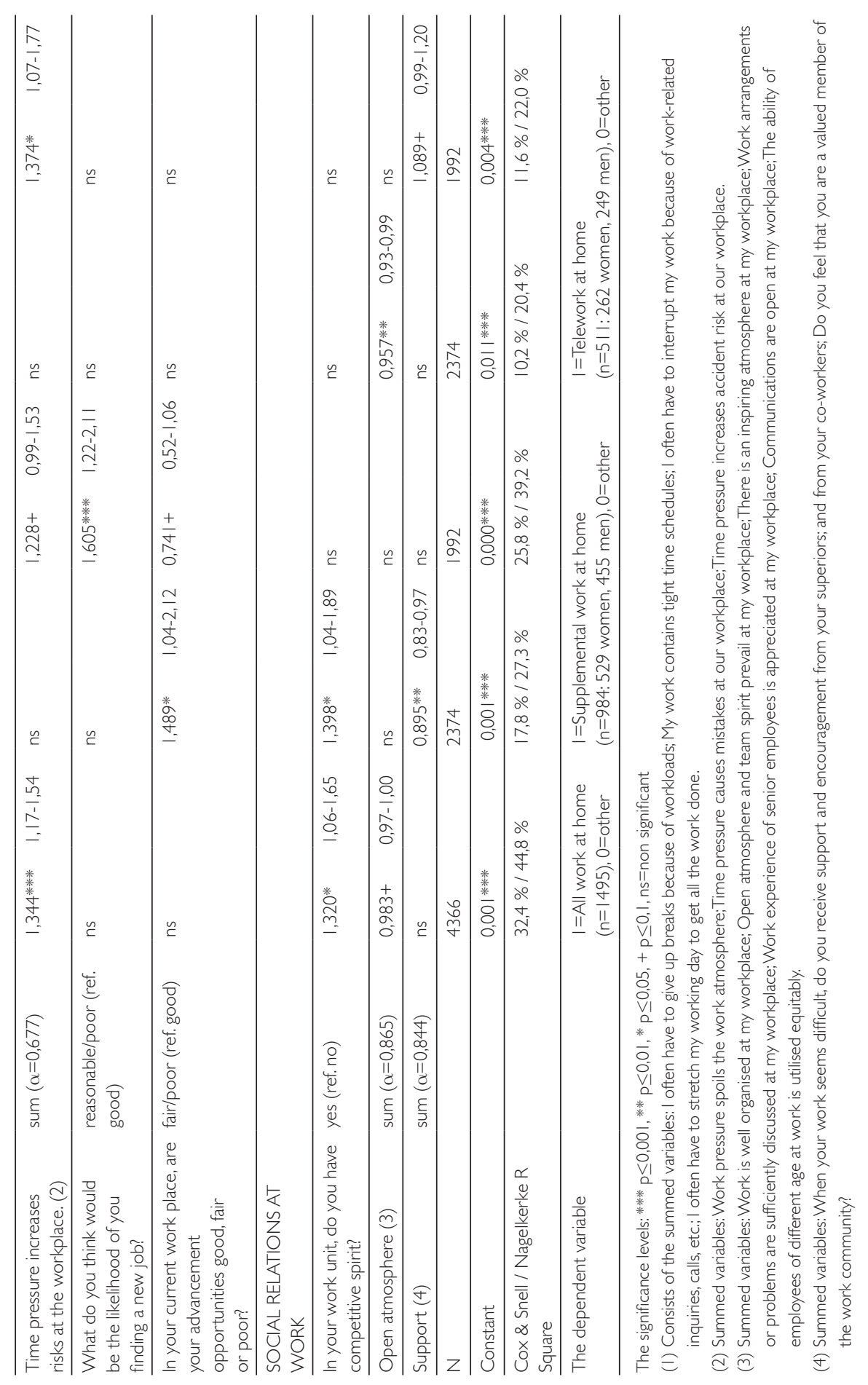


The cross-sectional quantitative data directed at the working conditions in general gave an overall understanding over the factors related to informal and formal patterns of working at home. The main difference is a result of time pressure, which the supplemental workers report significantly more often than teleworkers. The data was chosen due to the generalizability of the results; however, it was not sufficient to measure the intricate nature of supplemental work. There was also a slight discontinuation between the two types of data used. In future, research settings that focus strictly on informality at work are needed. The gender differences found in these analyses are, within the limits of this data, preliminary and serve as the basis for further exploration.

\section{Discussion}

There is no doubt that present-day work carries over into employees' private spheres. The aim of this article was to understand why employees undertake supplemental work actions, after or before their actual working time, at home, and what factors in general are related to supplemental and telework, and finally, whether gender is connected with informal overtime work at home.

All in all, work at home is more often informally constructed overtime work than agreement-based telework during normal work hours. A high-level labour market position and having autonomous and creative work content are the strongest predictors of all work at home. However, especially supplemental work is a two-edged phenomenon by nature. The results suggest that supplemental work may mostly be an outcome of time pressure, tight deadlines and a heavy workload. Even if work allows and encourages freedom and autonomy, it usually necessitates personal responsibility and the selfassessment of results. Thus, some of the experienced urgency may act as a surface for more qualitative senses of ineffectiveness, problems in managing workdays productively associated with lack of adequate skills when faced with demanding tasks. Fenner and Renn (2010) even found, that employees who do supplemental work reported less workfamily conflict if they had stronger skills in defining and prioritising tasks.

According to the qualitative results, a long-hours work culture and informal organizational practices may sometimes push employees into doing involuntary overtime. However in the quantitative analysis, social relations, including the atmosphere and the support of superiors and the work community are only weakly related to supplemental work. Hence, supplemental work appears to take place mainly if the workload grows temporarily high and/or if personal motivation allows it. I suggest that the carrying out of supplemental work at home comprises of a multi-level and interactive amalgamation of both fascinations and pressures that lie with employees themselves, in their organizations and in society. Employees evaluate and respond to this often conflicting complexity in many ways.

A critical finding is that no explicit gender differences were found. As also evidenced by Song (2009) and Atkinson and Hall (2009), work itself and its characteristics shape the choices concerning working spaces the most. The Nordic labour markets, providing comparatively intense egalitarianism with high levels of educated women and female labour force participation rates, may operate as a basis for the result: in white-collar work, which is the main situation for women working at home in Finland, women are perhaps overtaking men as regards of availability of choices concerning working time and placefor better and for worse. Drawing from Hakim's (2002) characterizations of personal life styles, the Finnish data used, both qualitative and quantitative, reflect a white-collar 
dual-earner model in which both women and men perform an 'adaptive' labour market strategy and prefer combining work and family rather than stressing one over the other (see also Halford 2005). Thus there is no reason for abandoning studying gender in the context of informal work; the statistical averages cover a wide variation of workplaces, individual situations in the context of household characteristics, partners' affiliation to labour market, the type of gender contract in the family (Sullivan and Smithson 2007), and finally, perceptions in work and life.

There is a growing understanding about the consequences the unlimited nature of work produces for employees and their families. The presence of work-related technology and the absence of temporal and spatial boundaries of work may lead to difficulties in separating between different life spheres, and aside from this fact, the family members need to negotiate the domains of work again (Felstead et al. 2005, p. 44; Jokinen 2009). Prolonged working hours may increase difficulties with detaching from work and the need for coping strategies against stress (Bird and Schnurman-Crook 2005).

Indeed, if telework can be seen as being at the border between home and work, supplemental work crosses the border into the heart of the home space. The role of home as a space for recovery may change. However, these discourses sometimes carry along a statement that all flexibility would take place at the expense of employees, women and families. This data both supports and challenges these assumptions; it seems that skills, personal boundaries and willingness to maintain them differ significantly. Most employees feel the need in principle to restrict work to the workplace and keep their private spheres separate, but at the same time, only a few clearly maintain those boundaries. It has to be accepted that the indefinite nature of much work today does not allow the work processes to be strictly controlled or guided. Halford (2005) also recognizes the diminished need for clear boundaries; and suggests that researchers give up the 'popular orthodoxy' of yearning for them. The acquired levels of autonomy are thus highly valued by employees and it gives them satisfaction and the possibility to further develop in their work (Green 2006; Lehto and Sutela 2008).

Nevertheless, to avoid an over-burdensome need for informal work that risks the well-being of some employees, the already high levels of informal actions at work should be reacted to at both the society and organizational level. The dispersing forms of work are mostly not recognised in labour law or work-time regulations (Supiot 2001). Amongst the many different arrangements of work at separate places, only telework is included in the European Trade Union Confederation framework agreement (ETUC 2002), which is an important step towards controlling new forms of work. In addition, at the organizational level, employers could aim at improving employees' skills in order to maintain the psychological boundaries of work. Working time and tasks should get actively discussed and formulated. Practical tools may be obtained with for example planned social employment protection (Janhonen et al. 2005) in cooperation with the health and safety organizations. To conclude, a positive and supportive atmosphere at the workplace may create a circle in which informal reciprocal flexibility every now and then ultimately works to the advantage of both employer and employee.

\section{Acknowledgements}

The study is funded by the Academy of Finland and the Finnish Work Environment Fund. 


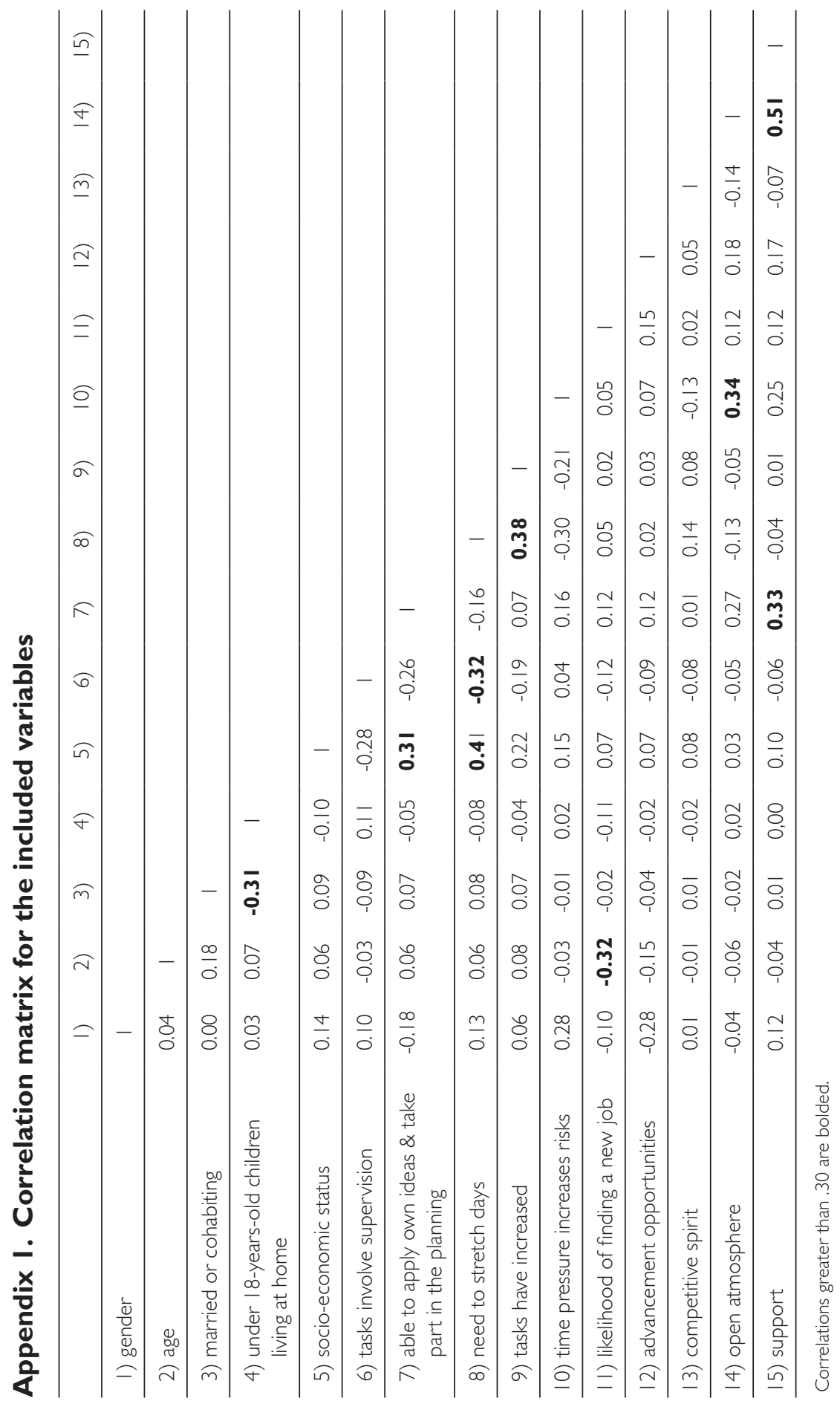




\section{Appendix 2. List of controlled but non-significant variables}

ORGANISATION AND JOB CHARACTERISTICS: Is your current employer: the state, a municipality or a joint municipal board, or a private sector employer?; Approximately how many persons altogether work for this employer in all its establishments?; In the last three years, has the number of employees at your establishment: increased, remained unchanged, or decreased?; In your opinion, is the financial position of your workplace at the moment: completely stable and secure, fairly stable and secure, slightly insecure, very insecure?; During the past three years, has the financial situation at your workplace: improved, remained unchanged, or worsened?; Over the past three years, have any of the following changes taken place at your workplace: A. Increased assessment or monitoring based on the productivity and results of work? B. Is work previously done in-house increasingly being outsourced?; Have any of the following major changes taken place at your workplace in recent years or any of them going to take place in the next few years: A. Change of superior or management? B. Change in ownership relationships of workplace? C. Change in information systems? D. Change in customer groups or products? E. Other major organisational changes?; Is your current employment relationship valid until further notice or fixed-term?; Is there a payment by results system in use at your workplace?; Do you work in a permanent work group or team that has common tasks and possibility to plan its work?

SOCIAL RELATIONS AT WORK: In your work unit, do you have a lot, quite a lot, some, or none of the following: Conflicts between superiors and subordinates? Conflicts between employees? Or conflicts between employee groups at your workplace?; Please indicate the extent to which you agree or disagree with statements concerning your immediate superior. A. My superior supports and encourages me? B. My superior rewards good work performances? C. My superior is inspiring? D. My superior discusses a lot with us? E. My superior speaks openly about everything concerning the workplace? F. My superior trusts his/her employees? G. There are a lot of conflicts between me and my superior? H. My superior does not care about the employees' feelings? I. My superior encourages his/her subordinates to study and develop in their work? J. My superior knows my tasks very well? K. My superior gives sufficient feedback about how well I have succeeded in my work? L. My superior delegates responsibility sensibly to the subordinates M. My superior is capable of settling conflicts between employees? N. My superior treats ageing employees equitably O. My superior treats women and men equally?

\section{References}

Akava (2008) 'Työaikoihin saatava tiukempi kontrolli' (Increased control for working hours needed). Newsletter given by the Confederation of Unions for Professional and Managerial Staff in Finland. URL: [http://www.akava.fi/ajankohtaista/uutisarkisto/2008] (15 August 2011)

Alvesson, M. (2004) Knowledge work and knowledge-intensive firms. Oxford: Oxford University Press.

Atkinson, C. and Hall, L. (2009) 'The Role of Gender in Varying Forms of Flexible Working', Gender, Work and Organization 16(6): 650-666. 
Bird, G. and Schnurman-Crook, A. (2005) 'Professional Identity and Coping Behaviors in Dual-Career Couples', Family Relations 54(1): 145-160.

Boswell, W. R. and Olson-Buchanan, J. B. (2007) 'Attitudes and Work-Life Conflict The Use of Communication Technologies After Hours: The Role of Work Attitudes and Work-Life Conflict', Journal of Management 33(4): 592-610.

Campbell, I. and van Wanrooy, B. (2010) 'Untangling the autonomy paradox: Why do some employees work extra unpaid hours in their jobs?' Presentation in Work, Employment \& Society Conference, 7-9 September 2010, Brighton, UK.

van Echtelt, P. E., Glebbeek, A. C. and Lindenberg, S.M. (2006) 'The new lumpiness of work: explaining the mismatch between actual and preferred working hours', Work, employment and society 20(3): 493-512.

ETUC (2002), Framework agreement on telework. URL: [http://www.etuc.org/a/579] (30 November 2009)

Felstead, A., Jewson, N. and Walters, S. (2005) Changing places of work. Basingstoke: Palgrave Macmillan.

Fenner, G. H. and Renn, R. W. (2010) 'Technology-assisted supplemental work and workto-family conflict: The role of instrumentality beliefs, organizational expectations and time management', Human Relations 63(1): 63-82.

Green, F. (2006) Demanding work. The paradox of job quality in the affluent economy. Princeton (N.J.): Princeton University Press.

Hakim, C. (2002) 'Lifestyle Preferences as Determinants of Women's Differentiated Labor Market Careers', Work and Occupations 29(4): 428-459.

Halford, S. (2006) 'Collapsing the Boundaries? Fatherhood, Organization and Home-Working', Gender, Work and Organization 13(4): 383-402.

Hislop, D. (2008) 'Conceptualizing Knowledge Work Utilizing Skill and Knowledge-based Concepts. The Case of Some Consultants and Service Engineers', Management Learning 39(5): 579-596.

Hislop, D. and Axtell, C. (2007) 'The neglect of spatial mobility in contemporary studies of work: the case of telework', New Technology, Work and Employment 22(1): 34-51.

Janhonen, M., Johanson, J. and Nikkilä, R. (2005) 'Verkostot ja sosiaalinen työsuojelu' (Networks and social employment protection), Työelämän tutkimus 2005 (1): 48-52.

Jokinen, E. (2009) 'Home, Work and Affects in the Fourth Shift', in Johansson, H. and Saarikangas, K. (eds.) Homes in Transformation. Dwelling, Moving, Belonging. Helsinki: Finnish Literature Society. 358-375.

Julkunen, R., Nätti, J. and Anttila, T. (2004) Aikanyrjähdys. Keskiluokka tietotyön puristuksessa. (Time twist. Middle class squeezed by knowledge work.) Tampere: Vastapaino.

Kossek, E. E., Lautsch, B. A. and Eaton, S. C. (2006) 'Telecommuting, control, and boundary management: Correlates of policy use and practice, job control, and work-family effectiveness', Journal of Vocational Behavior 68(2): 347-367.

Lehto, A.-M. and Sutela, H. (2008) Three decades of working conditions. Findings of Finnish Quality of Work Life Surveys 1977-2008. Helsinki: Statistics Finland.

Mirchandani, K. (2000) “"The Best of Both Worlds” and "Cutting My Own Throat”: Contradictory Images of Home-Based Work', Qualitative Sociology 23(2): 159-182.

Morganson, V., Major, D., Oborn, K., Verive J., and Heelan, M. (2010) 'Comparing telework locations and traditional work arrangements. Differences in work-life balance support, job satisfaction, and inclusion', Journal of Managerial Psychology 25(6): 578-595.

Nätti, J., Anttila, T., Ojala, S. and Tammelin, M. (2009) Paid Work at Home. In Virolainen, H., Sirkemaa, S. and Vartiainen, T. (eds.) The Proceedings of the 14th International Conference on Telework - ITA2009. Turku: Turku Centre for Computer Science. 173-185.

Nätti, J., Tammelin, M., Anttila, T. and Ojala, S. (2011) 'Work at home and time use in Finland', New Technology, Work and Employment 26(1): 68-77. 
O’Carroll, A. (2008) 'Fuzzy Holes and Intangible Time: Time in a knowledge industry', Time \& Society 17: 179-193.

Parent-Thirion, A., Macías, E. F., Hurley, J. and Vermeylen, G. (2007) Fourth European Working Conditions Survey. Dublin: European Foundation for the Improvement of Living and Working Conditions.

Pyöriä, P. (2006) Understanding Work in the Age of Information. Finland in Focus. Acta Universitatis Tamperensis 1143. Tampere: Tampere University Press.

Rita, H. and Komonen, A. (2008) 'Odds ratio. An ecologically sound tool to compare proportions', Ann. Zool. Fennici 45: 66-72.

Sennett, R. (1998) The corrosion of character. The personal consequences of work in the new capitalism. New York: Norton.

Song, Y. (2009) 'Unpaid Work at Home', Industrial Relations 48(4): 578-588.

Sullivan, C. (2003) 'What's in a name? Definitions and conceptualisations of teleworking and homeworking', New Technology, Work and Employment 18(3): 158-165.

Sullivan, C. and Smithson, J. (2007) 'Perspectives of homeworkers and their partners on working flexibility and gender equity', International Journal of Human Resource Management 18(3): 448-461.

Supiot, A. (2001) Beyond Employment. Changes in Work and the Future of Labour Law in Europe. Oxford - New York: Oxford University Press.

Thompson, P. (2003) 'Disconnected capitalism: or why employers can't keep their side of the bargain', Work, employment and society 17(2): 359-378.

Vittersø, J., Akselsen, S., Evjemo, B., Julskrud, T. E., Yttri, B. and Bergvik, S. (2003) 'Impacts of Home-Based Telework on Quality of Life for Employees and their Partners. Quantitative and Qualitative Results from a European Survey', Journal of Happiness Studies 4: 201-233.

Wight, V. R. and Raley, S. B. (2009) 'When Home Becomes Work: Work and Family Time among Workers at Home', Social Indicators Research 93(1): 197-202. 